\title{
Lupus senkt den Blutzucker?
}

\author{
Patientin B. H. 48 Jahre, 54kg schwer, $162 \mathrm{~cm}$ groß.
}

Eine kurze Beschreibung eines Falls soll Anstoß für eine fachliche Debatte sein, zu der wir Sie herzlich einladen.

In der Rubrik „aus der Praxis“ werden regelmäßig diagnostische und therapeutische Probleme dargestellt und Vorschläge für Lösungsmöglichkeiten angeboten.

Lassen Sie auch die Kolleginnen und Kollegen an Ihren Überlegungen teilhaben und kommentieren Sie! Hinweise, wie Sie Ihre Beiträge übermitteln können, finden Sie am Ende des Artikels beim QRCode. Wir freuen uns auf Ihren Beitrag.

\section{Anamnese}

Zum Zeitpunkt der Erstaufnahme (2007) präsentiert sich die Patientin mit Arthralgien, Schmetterlingsexanthem sowie nächtlichen Fieberschüben. Die Verdachtsdiagnose war daher systemischer Lupus erythematodes.

Laborbefunde: ANA pos., DNA-AK pos., SSA und SSB pos., AK gegen Nukleosomen pos., C3 und C4 deutlich erniedrigt, Leukopenie. Erhöhte Eiweißausscheidung mit $~ 500 \mathrm{mg}$ EW im 24-Stunden Harn als Hinweis auf eine Nephropathie. Die Arthralgien betreffen Schultergelenke, Ellbogengelenke, Handgelenke, sämtliche MCP sowie PIP Gelenke, weiters beide Knie und Sprunggelenke druckschmerzhaft, nicht geschwollen. Morgensteifigkeit etwa fünf Stunden, Schmerzpessimum morgens.

Somit ergeben sich fünf ARA Kriterien positiv, und die Beschwerden der Patientin können als Lupus erythematodes klassifiziert werden.

\section{Erste Therapie}

Die Patientin erhält zunächst eine Therapie mit MTX und Cortison. Eine Umstellung nach einem neuerlichen Schub auf Imurek musste wegen iatrogener Hepatopathie abgesetzt werden.

Nach Auftreten eines Lungeninfarktes als Folge eines sekundären Antiphospholipidsyndromes wird die Patientin marcoumarisiert und auf Cyclosporin A und Cortison umgestellt.

\section{Rezentes Problem}

Die Aufnahme erfolgt im Rahmen eines neuerlichen Schubes mit Febrilitäten, Arthralgien und reduziertem AZ.

Primär erfolgt eine Erhöhung der Cortisondosis auf $37,5 \mathrm{mg} / \mathrm{Tag}$. In weiterer Folge entwickelt die Patientin eine zerebrale Symptomatik und ist schließlich nicht mehr ansprechbar. Als Ursache findet sich eine deutliche Hypoglykämie mit Werten unter $40 \mathrm{mg} \%$.

\section{Differentialdiagnosen}

- Insulinom

- Malabsorption

- Pankreatitis

- Autoimmunität

In einer Pankreas-CT findet sich weder Zeichen einer Pankreatitis noch einer Raumforderung im Sinne eines Insulinomes.

Insel-Zell Antikörper und Insulin Auto-AK sind negativ, überraschend jedoch finden sich für Insulin und C-Peptid Werte knapp oberhalb der Nachweisbarkeitsgrenze.

\section{Mögliche Erklärung}

In der Literatur finden sich vereinzelt Hinweise auf das Auftreten stimulierender Insulin-Rezeptor-Autoantikörper bei Patienten mit Autoimmunerkrankungen.

Binden sich diese Antikörper an den Insulinrezeptor werden hohe Insulinspiegel simuliert, der Blutzucker sinkt ab und die endogene Insulinproduktion geht gegen Null. Somit geraten die Patienten in eine protrahierte Hypoglykämie. Diese Insulin-Rezeptor Antikörper konnten zum Zeitpunkt der Diagnose in Österreich nicht bestimmt werden, somit gründete sich das weitere Vorgehen auf diese Verdachtsdiagnose.

\section{Therapie}

Die Patientin erhielt 2x500mg Prednisolon i.v./die, in weiterer Folge als orale Dauertherapie $75 \mathrm{mg}$ /die (mit dem Versuch einer

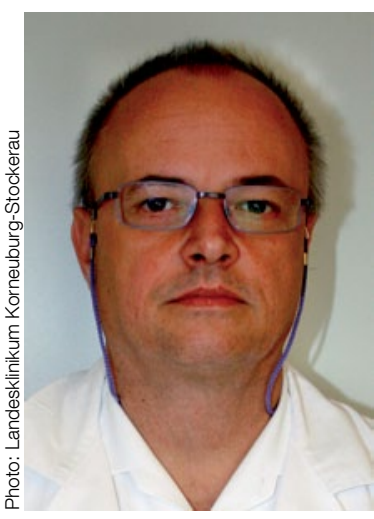

OA Dr. Thomas Svoboda

Niederösterreichisches Kompetenzzentrum für Rheumatologie, 2000 Stockerau

Reduktion im ambulanten Bereich). Weiters 500mg Cyclophosphamid i.v. 1x/Monat über 6 Monate.

Unter diesem Therapieregime stellten sich zufriedenstellende Blutzuckertagesprofile ein, ebenso kam es in Hinblick auf den Lupus erythematodes zu einer deutlichen Besserung der Klinik und Befunde.

Bei Unverträglichkeiten von Mycophenolat, Mofetil und auch Rituximab steht die Patientin derzeit unter Belimumab, Hypoglykämien sind seit der EndoxanTherapie nicht mehr aufgetreten.

Diesen Artikel aus der Rubrik

„Aus der Praxis“ finden Sie auch online unter www.springermedizin.at/ schwerpunkt/rheumatologie oder sie gelangen mit Hilfe des QR-Codes fürs Handy oder einen Tabletcomputer direkt zum Artikel. Dort können Sie Ihre Überlegungen

bzw. Kommentare

posten.

Oder Sie schreiben

eine E-Mail an:

leeb.rheuma@aon.at 